\title{
Regional development the Cree of James Bay, Quebec
}

\begin{abstract}
Mike McGee, Ec.D.
This paper will focus on how the Cree have had to adapt and put in force various policies and measures that they felt would best serve their people after the signing of the James Bay and Northern Quebec Agreement. The material that was researched, as well as the author's personal experience, will provide an insight into how the Cree set up their own government structures, businesses and institutions since the signing of the agreement. Through a historical examination of their advancement to modern day society and advanced technology, this paper will demonstrate how the Cree have maintained their traditions, culture and beliefs by dealing with their own issues and problems from within. The paper concludes with a number of observations and recommendations.
\end{abstract}

Keywords: Aboriginal, Cree, regional and social development, government

\section{Introduction}

This paper will focus on how the Cree have had to adapt and put in force various policies and measures that they felt would best serve their people after the signing of the James Bay and Northern Quebec Agreement. The material that was researched, as well as the author's personal experience, will provide an insight into how the Cree set up their own government structures, businesses and institutions since the signing of the agreement. The author has lived and worked in James Bay for the past 19 years and has been employed for the past 10 years as the Director of Economic Development for the Cree Nation of Wemindji. Being also part of the community through marriage, the author has also been actively involved in many of the decision-making processes within the Cree government and local Band Council. This paper will try to demonstrate the means by which the Cree people deal with their own issues and problems from within. The paper concludes with a number of observations and recommendations.

\section{Objectives}

The general objective of this research is:

- To examine the social and economic development processes that occurred in the Cree communities of James Bay.

- To evaluate the social development planning and implementation as well as the economic development planning and implementation processes that contributed the most to success or failure in achieving the goals set by the Cree people. 
- To assess the impact of both internal and external influences on achieving social and economic goals.

- To establish the extent and nature of community involvement and participation in the development process.

- To determine the extent to which there is an overall strategic development plan for the communities, and for the region as a whole.

- To explore the extent to which economic and social objectives have been met.

\section{Historical perspective}

Nothing has so drastically impacted or negatively affected the Cree nation and their land as the arrival of the Europeans. The inevitable clash of cultures has taken a toll on the Cree people. Since contact with the Europeans, the control of Cree lands and its resources has been an issue of contention. The Cree people have endured as a people in spite of all that they have faced. Their continued existence attests to their resiliency and perseverance.

The Cree Nation consists of approximately 12,000 aboriginal people of Cree ancestry. Subject to their own laws, customs and beliefs, through time the Cree Nation has lived, hunted, fished, trapped and harvested in the James Bay and Hudson Bay territory.

The Cree Nation has held aboriginal title to its traditional ancestral lands, an area east of James Bay and Hudson Bay. This title was confirmed by common law, under the Royal Proclamation of 1763 and other laws, and legislated by the James Bay and Northern Quebec Agreement (1975) and related Canadian legislation.

The Cree have used, managed, conserved, and depended on the water, land and wildlife of the territory for more than 5,000 years. The Cree land and way of life has in recent years been greatly altered by hydroelectric development authorized by the Governments of Canada and Quebec. A new series of proposed hydroelectric development projects further threatens the environment of James Bay, and endangers the cultural survival of the Cree people.

\section{The agreement}

The James Bay and Northern Quebec Agreement (JBNQA) was a major turning point for the Cree of James Bay. The Agreement was the first treaty Quebec signed with the Federal Government and Aboriginal Nations, and specifically the Cree and the Inuit.

On the evening of April 30, 1971 Quebec Premier Robert Bourassa unveiled plans created by Hydro-Quebec for a hydro-electric project that would dam several rivers in Northern Quebec, create tens of thousands of jobs and create a new trade base for Quebec in surplus power for 
export and to entice investment. Two months later, the feasibility study being conducted by Hydro-Quebec had not even been completed, however, the construction of roads into the James Bay area had already started. Bourassa saw this project as a way of creating much needed jobs and increasing the economic autonomy of the Province of Quebec

This project, it was thought, would be good for Quebec. Thousands of jobs would be created, the power needs of the province would be taken care of, and there would even be a chance to export power to the United States. Additionally, hydroelectric power has always been thought of as relatively inexpensive in the long run, and, apart from the destruction of the natural habitat from the flooding of reservoirs, environmentally sound.

The James Bay Project became controversial because of the considerable stakes involved. Hydro-Quebec, the state-owned utility company that supervised the construction, was the primary engine of economic growth for Canada's Francophone province.

Nevertheless, the James Bay and Northern Quebec Agreement was ratified and signed on November $11^{\text {th }}, 1975$ and was one of the most significant treaties ever signed with aboriginal people in Canada. Under the Agreement, the Cree and the Inuit assumed major responsibilities in education, health services and social services, administration, hunting, fishing and trapping. The Agreement also made a provision for administrative structures and funding needed to enable the Cree and the Inuit to take on these responsibilities. In return, the aboriginal people released their rights to almost one million square kilometers of land. Quebec could then develop the land in accordance with the rules set out in the Agreement.

The original plan for Phase I called for the building of four powerhouses with dams and the flooding of more than 10,000 square kilometers of land along the La Grande river, Quebec's third largest river, and the largest river flowing into the James Bay. Now completed, Phase 1 of the project has a generation capacity of over 10,000 megawatts of power and cost an estimated $\$ 16$ billion to build.

The second part of the James Bay Complex, known as James Bay II, calls for the development of generating systems along the Great Whale River to the north of the La Grande river, and the combination of the Nottaway, Broadback, and Rupert Rivers to the south. Hydro-Quebec sees the development of these rivers as necessary for keeping up with the future power needs of Quebec. It appears that Quebec-Hydro would use the extra capacity for the sole purpose of exporting power to the United States. In doing so, Hydro-Quebec overcharges its U.S. customers, and artificially lowers the cost of power to people in Quebec.

Northeastern Canada has, per unit of surface area, more flowing water than almost anywhere else on the globe. It is in the many rivers flowing into the James Bay and Hudson's Bay that 
industrialists and politicians saw the potential to spur economic growth in the Province of Quebec. Hydro-Quebec, government owned since 1963, embarked on a mission to transform the natural waterways into a system of dams and reservoirs to generate electric power for Canada and the United States. The James Bay hydro-electric projects have stimulated worldwide debate.

Decomposition of trees as a result of flooding creates a highly toxic form of mercury, methylmercury, which is passed down the food chain. The Cree people whose diets are based on fish are poisoned, as are endangered species such as the Beluga whale and the fresh water seal. A major concern related to the disruption of the balance of a complex hydraulic cycle, while is not completely understood, is the potential impact on weather patterns. Hydro-Quebec has also indirectly harmed the environment through its contracts with aluminum companies and other polluting customers who buy their power. The level of mercury in the environment is already well above those internationally regarded as being safe, and the number of cases of mercury contamination exceeds World Health Organization standards. Hydro-Quebec believes that other than the habitat damage from the reservoirs, there will be little adverse environmental and social impact, and that mercury levels will drop in 20-30 years. Others estimate that the mercury levels in the reservoirs will not drop for 80-100 years. Studies conducted at the Experimental Lakes Area, in northwestern Ontario, found that hydro-electric dams, like those that Hydro-Quebec have created in the James Bay Area, emit as much greenhouse gas as a fossil fuel plant.

Since the early 1970s the Cree have been struggling to protect their lands or at least receive compensation. The 1975 James Bay and Northern Quebec Agreement between Hydro-Quebec and the Cree was thought to be a solution to the conflict between the two interests. However, the Cree believe the utility company has violated the agreement by not performing environmental impact assessments and by beginning the construction of more power generating plants despite low demand. Hydro-Quebec contends to the contrary, that it was understood in the agreement that Hydro-Quebec could complete its foreseen project, including one on the Great Whale River.

The culture of the Cree and the Inuit is threatened. As nomadic hunters in an environment with scarce resources, they require large spaces of land. A large proportion of their campsites, trapping land and burial sites have been submerged. In addition, as development proceeds and more Canadians inhabit Northern Quebec, the traditional ways of the Indians are being eroded and replaced with the social ills of modern society. Similar to the plight of American Indians in the U.S., drug and alcohol abuse, crime and sexually transmitted diseases, as well as disease stemming from poor diets, are prevalent among the Cree and the Inuit.

Financial compensation for their losses has made these people dependent on the government. Hunting is no longer central to their existence because it is not economically viable and constrained by the development of infrastructures. They find themselves at a low rank of society, unskilled, unemployed and under-educated and suffering from a loss of identity and self- 
worth. Ironically, those who have struggled the most to preserve their traditional hunting and culture have had to abandon it in order to deal with developers and the government on equal footing. Skills in lobbying, law, economics and public relations are now crucial to the Cree and the Inuit.

When the La Grande project broke ground, many of the people in the area were never even told about the plans. Some actually found out about the project when they read about it in the newspaper. To this hunting culture, the flooding of ancestral burial grounds and traditional hunting areas would prove devastating. In the words of Mathew Coon Come, Grand Chief of the Cree: "Our land is our memory." The International Water Tribunal ruled that Hydro-Quebec should stop any further developments of the James Bay Project in order to preserve the rights and culture of the native people.

\section{Political perspective}

The central Cree political body is the Grand Council. The council has twenty members: a Grand Chief and Deputy-Grand Chief, each of the chiefs from the nine Cree communities, and one other representative from each community. The Council was formed in 1974 when the Cree were negotiating with the Quebec and Canadian Governments about Cree rights in relation to the James Bay hydroelectric development plan.

The James Bay and Northern Quebec Agreement established a number of formal bodies through which the Cree relate to the Euro-Canadian world that has progressively invaded the James Bay territory. The central of these formal bodies is the Cree Regional Authority (CRA), which was incorporated in 1978 through an Act of the Quebec National Assembly. The Cree Regional Authority represents the regional government responsible for the administration of the James Bay and Northern Quebec Agreement.

From the beginning the Cree decided that the membership of the CRA should be identical with the membership of the Grand Council, thus assuring co-ordination between political objectives and administrative actions. So the CRA Council, like the Grand Council, is comprised of a band chief from each of the nine communities, and one other member from each community, in addition to the Grand Chief and Deputy Grand Chief, who are elected directly at the Cree Annual General Assemblies.

The CRA has broad-ranging responsibilities for ensuring that the many provisions of the JBNQA designed to protect and enhance Cree life are implemented. It works with all departments of the federal and provincial governments to ensure protection and implementation of Cree rights. Furthermore, it works with Cree boards to ensure that the collective rights of the Cree are respected and promoted. 
Groups are forming networks to lobby against the James II project, including the James Bay Defense Coalition and the New England Energy Efficiency Coalition, coal mining interests in the United States and political activists in both Canada and Northern U.S. states. In the early 1990s, the Sierra Club, PROTECT and the Cree took legal action (to no avail) against the New York Power Authority arguing that imported electricity should be subject to similar environmental standards as in New York.

In the push for public awareness, the Cree and Inuit have appealed to the people in the U.S. states to which Hydro-Quebec would sell power. The states in New England provide HydroQuebec with huge potential markets for the power generated at James Bay, and because the rates are artificially inflated to subsidize the power costs of Quebecers; these states represent a huge potential profit. By appealing to the citizenry of these states, the Cree have a chance to take from Hydro-Quebec a portion of its potential revenue. In New York, former Governor Mario Cuomo cancelled an estimated $\$ 17$ billion contract with Hydro-Quebec when the New York State Legislature passed a law requiring the state to explore conservation and alternative energy sources before importing power. Other power companies claim that there will be little or no need for Quebec power in their service areas, and that they too will market surplus power to companies in neighboring states. This will further reduce Hydro Quebec's justification for expanding production facilities in the James Bay area.

A Supreme Court decision in Ottawa illustrates the tensions between Quebec's drive for independence and the drive for self-determination by the Cree. In 1990, the National Energy Board granted Hydro-Quebec a license to export electricity to New York and Vermont provided that the production of electricity did not conflict with relevant environmental standards and that an environmental assessment was performed (by the national government) to determine that there were no violations. Quebec appealed this decision on the grounds that the whole James Bay Project was being subjected to federal control and eventually won. The Cree brought the case to the Supreme Court. The Court ruled that a federal review of Hydro-Quebec dams is required, if they are connected to export contracts. Although a victory for the Cree, they could not convince the Court that licenses to export be completely revoked.

Being a primarily French-speaking province, Quebec is culturally different from the rest of Canada and has long expressed a desire for independence. Its need to remain autonomous, which might in part be achieved through Hydro-Quebec's project, is a very strong force driving Quebec's separatist movement. In the pursuit of its own cultural and economic autonomy, Quebec is denying autonomy to the indigenous peoples of Quebec.

The Cree School Board, with jurisdiction over elementary, secondary, post-secondary and adult education services within the James Bay territory of Quebec, provides its services in English as 
well as French and Cree. The Cree School Board has established control over language and curriculum and is the primary vehicle for the preservation and development of Cree culture, language and history. The responsibilities and special powers of the Board are extensive and were developed on the basis of the specific educational needs of the Cree. The ongoing control of the education system will enhance and support the potential for the Cree to achieve their future objectives in Quebec.

There has been a lot of attention devoted to the development of an autonomous Cree justice system in recent years. There are particular characteristics of Cree people and communities, which, although not directly related to justice, have important implications for a Cree justice system. These factors mitigate against the ability of any formal, regional structure, to solve the broad range of complex justice and community problems. A formal Cree justice system has many potential benefits but it is important to distinguish the problems it can address from those it cannot. Cultural and traditional differences must be accommodated to ensure a system that will have legitimacy, credibility and reflects a range of interests and ideologies.

Approximately 20 per cent of Canada's total population is comprised of French speaking people. As a result, the Canadian Federal government has passed laws, which make French the second official language of the country, giving it the equivalent status to that of English. The Cree people living in Quebec fear that without federal protection, an independent Quebec will ignore their rights. The Cree and Inuit claim that they will secede from Quebec if Quebec separates from Canada, and may, in the extreme, threaten to plunge Quebec into a civil conflict with secessionist native peoples.

\section{Developments}

Since The Agreement, the Cree have, put in place many organizations and entities to help with the implementing of the plan of action proposed by the JBNQ agreement. Several factors and constraints influence the economic development of the Cree communities.

The majority of the communities are small and far from market areas and suppliers. Out of the nine Cree communities, two communities still have no access by road at all, with access offered strictly through air travel. Many of the working age population do not have any secondary school diplomas and thus their opportunity for vocational training is limited. The lack of skilled labour makes it difficult to create stable and well-paying jobs.

In most communities the Band Council has usually been the main employer. Work exists in municipal infrastructure and services, such as water and sewage systems, housing and road maintenance. In recent years however, the Cree have increasingly emerged as leading business leaders in the James Bay region as well as in Quebec as a whole. The Cree have achieved a solid 
reputation in the areas including air transportation, construction, forest management, fuel distribution and outfitting.

The following is a sample of the businesses that the Cree own and operate.

\section{Regional developments}

- Cree Regional Authority; Administrative Body for the Cree

- Grand Council of the Crees; Political body for the Cree

- Creeco: Cree Regional Economic Enterprises Company; a regional business development entity and holding company.

- Cree Construction \& Development; a general contractor for all construction projects both large and small. Also active in promoting economic development initiatives.

- Servinor; a food wholesaler and supplier for all of Northern Quebec, including Cree grocery stores as well as Inuit Cooperatives.

- Valpiro; an airport cargo handling company.

- Cree Energy; a regional petroleum distribution company which supplies fuel to all gas stations, airports and depots in James Bay.

- Air Creebec; a James Bay regional airline providing daily scheduled service between all the Cree communities.

- Cree Board of Health and Social Services; A regional health board that has a clinic in each community and one hospital in Chisasibi. Provides full medical coverage for everyone, free of charge. Also responsible for mental health as well as dental services, at no cost to the individual.

- Cree School Board; The regional education board represents all communities providing complete schooling from kindergarten through to grade twelve. The school board also provides funding and assistance for college and university students as well as adult education services. All services are provided free to all students.

- James Bay Cree Communications Society; a radio and television company that broadcasts daily throughout all the Cree communities in the Cree language.

- Cree Board of Compensation; a capital corporation created with funds from various Agreements. Communities receive annual amounts from the Board to help develop community projects and infrastructure.

- Cree Trappers Association; a regional support association to provide services and assistance to those who still practice the traditional way of life.

- Cree Human Resources Department; a regional funding department of the CRA that concentrates on the training of Cree people to be able to obtain employment in various fields.

- Eeyou Economic Group; a regional loan fund corporation that provides loans and support services to Cree entrepreneurs. 
- Kepa Transport; a regional trucking company that is the exclusive cargo transporter of Northern Quebec.

- Air Wemindji; a regional charter and bush-flight airline that provides all necessary flights for hunters, trappers, tourists and contractors in the Region.

- WhapChiWem Helicopters; a regional helicopter company that offers a full range of helicopter services to hunters, trappers and contractors in the region.

- Beesum Petroleum; a regional petroleum distributor that supplies fuel and service to all gas stations and airports in the northern region of James Bay.

The approach taken by the Cree in developing their region recognizes that the small and medium size business sector represents the driving force in the region's economic potential. They further recognized the need for a coherent and concerted action with a series of partnerships in order to help realize regional development.

\section{Local developments}

In addition to many regional initiatives, the Cree have realized numerous changes in the municipal level. In the past 25 years, the Cree communities have changed dramatically. The rapid development of "modern" communities has been difficult to cope with, especially for the older members of the community who, for the most part of their lives, grew up in the bush. Without going into great detail, the following provides an indication of how the communities have developed locally.

The Cree community of Oujé-Bougoumou was the first in the continent to implement a villagewide district heating system based on biomass resources. The system generates hot water through a huge boiler that is fired by wood chips that are a by-product of the nearby forestry industry. This co-generation system heats the entire town. A large underground network of pipes routes the hot water to all the homes. The homes are installed with hot-water radiators that take in the hot water and circulate it throughout the home for heat. The hot water is also channeled in to the regular tap water and is also used for other domestic hot water demands. As

a result of their development, the community received a United Nations award in 1995 for being a "sustainable community." The project was pursued because of the environmental, community, economic development, and self-sufficiency benefits that it offered. In addition to the district heating system, all of the homes in Oujé-Bougoumou are designed to the highest energy efficiency levels, exceeding the R-2000 standard.

Recognizing the unlimited potential for development in the forestry sector, the community of Waswanipi negotiated with Aboriginal Business Canada a $\$ 5$ million dollar plan to build and operate a sawmill. The plan underwent an environmental impact assessment and following the release of the results, construction of the sawmill began in October 1996. The result was the 
creation of Nabakatuk Forest Products Inc. The company is a joint venture between Waswanipi Mishtuk Corporation and Domtar Inc. Funding was also received from the Waswanipi Band Council and Aboriginal Business Canada to build the sawmill.

Waskaganish expanded their horizons by investing in part-ownership of a marine shipping company. Moosonee Transport Limited, owned in part by the Cree of Waskaganish, operates several vessels and numerous barges throughout the James Bay and Hudson's Bay area during the summer months. They load their vessels in the ports of Moosonee, Ontario and Wemindji, Quebec and deliver materials and cargo to Inuit communities and other communities who do not have any road access. The company employs several Cree persons that work on the vessels. This operation continues throughout the months from June to November each year.

The community of Wemindji on the other hand, decided to undertake the unique task of constructing their own hydroelectric dam and generating station. Being strategically located on the shores of the Maquatua River, Wemindji had a perfect opportunity for such a project. With funds obtained through the complimentary agreement \#5 of the James Bay and Northern Quebec Agreement the community invested over $\$ 6.5$ million dollars and built a dam on the river. The resulting generating turbine is capable of generating sufficient electricity to serve the entire community. This was the first time in Canada that an Indian Band built, owned and operated a hydroelectric complex. The power-generating station still operates to this day and the residents of Wemindji have been enjoying low-cost electricity and employ their own people to manage the complex.

The Cree communities have developed rapidly over the recent years and all share multiple development achievements. Better homes have been built to accommodate the growth in population. More adequate and modern water and sewage systems are now installed in all the communities. They also boast the startup of commercial activities such as restaurants, hotels, gas station and taxi services, all located within each community. Some of the more populated communities have managed to establish shopping malls and various commercial centers. Banking services and automated teller machines are also available throughout the James Bay region.

Entrepreneurship has increased significantly in recent years and the Band Councils have set up local economic development corporations to handle this phenomenon. In all communities you will find modern office buildings, medical clinics and a hospital in two of the communities. The growth has also made it possible to incorporate a local police force. There are churches, schools and large community complexes for public gatherings and other events. Some communities along the coast have become involved in the marine shipping industry with multiple ships navigating throughout the James and Hudson's Bay. Others are involved in mining and 
exploration and have signed various agreements with mining companies as well as the development of the forestry industry, which has also become apparent in James Bay.

Most newcomers to the James Bay region are quite surprised to find that there are very few traditional dwellings to be found. Everyone now lives in comfortable modern houses just as in any urban society. There is satellite television throughout as well as local Internet access. The Cree "villages" or "bands" have been entirely transformed into communities and towns. As a matter of fact, the word "band" is almost never used any more. Instead, the Cree have chosen to call themselves a "nation" and not a "band". Each community is now called, for example, "the Cree Nation of Wemindji" or "the Cree First Nation of Waskaganish". The "band council" as it used to be commonly called has also been renamed to, "the Council of the Cree Nation of Chisasibi" or the Council of the Mistissini Cree Nation" and so on.

\section{Analysis}

Obviously all this development has induced significant changes in the lifestyles of the Cree people. Most people lived entirely in the bush not more than 40-50 years ago. Today many of these people living in new communities are faced with a whole new set of rules consistent with that of modern society. There still remains a lot of hate and resentment towards the non-natives. Many of today's problems are usually blamed on non-natives. The Cree have a lot of trouble accepting failure and will almost always search to blame someone else other than themselves. This inability to accept failure and or error is common and hampers development and progress, especially when a lot of time is spent on dealing with the past or trying to find someone to blame for their troubles.

One factor that hinders economic development is that the Cree people tend to base a lot of their decision-making on past issues. While it is true that there have been mistakes in the past, it is also true that life may never again be the way it was. Historically, the Cree would formulate their plans based on past experiences while hunting or fishing. This method of planning is not as effective in today's world and thus the Cree have had to learn a new way of planning that is based on a more futuristic approach. Another factor, which hinders modern development, is that educational background is not a requirement to being an elected council member on the Band Council. Many times the Band council member will be elected because they happen to have many friends or are part of a large family with many relatives. You will often see poor decision making on business planning due to the inability of the council members to properly asses the situation at hand. Although the people are generally quite good at analyzing environmental and wildlife issues, they are not as capable in the area of business planning. This also presents problems when trying to comprehend complex issues such as financial planning, forecasting, legal and political issues. The councils have maintained a strong interest in preserving their 
language, culture and traditions. This, however, often results in clashes with the demands of modern economic development.

With the bulk of the higher educated Cree people sitting on the regional boards, organization and entities, the result is a very much "top down" approach to development. Many reports point to consultations at the local level, however, the real decision-making is being performed from the top with the Cree leaders telling the people what is best for them. Is this really the best approach? Most Cree leaders now live in cities such as Montreal and Ottawa and have been out of their communities for many years. The influences of urban living, along with legal advice, consultants and so on have somewhat changed the way they used to think and have confused many Cree leaders. Many Cree leaders are more concerned with politics and modern day issues than the real interests of the people who are living on the reserves. A lot of development is also affected by the personal agendas of Cree leaders who now take advantage of personal gains from large development projects.

There has, up until now, been a lot of emphasis on the development of the service sector. There has been a noticeable lack of effort to develop commercial, industrial and natural resource opportunities. The services sector has been saturated and there is not much room left for further development in that area, other than perhaps tourism. The problem is that services require money to be invested without much return on the investment other than the service itself. More emphasis should be put on investing in businesses that can bring a cash return on the investments for years to come, in other words, investing for the future. More initiatives should be taken to investigate the potential of the renewable resource sector. The area of James Bay is home to thousands of kilometers of land, water, trees and minerals. There are many opportunities that have been ignored in that area. Opportunities such as the sale of water, mineral extraction and joint ventures in forestry and hydroelectric development are all possible.

The Cree communities have now learned about competition. Unfortunately this has led to communities not wanting to cooperate or work together. There is noticeable competition between Cree companies that provide the same service or product. Distrust between Cree business people is prevalent. Even Cree chiefs cannot come together and agree on certain issues and thus opportunities that could provide a significant improvement to the development of the region. Many issues become discarded, or just simply stalemated at the boardroom table. This lack of cooperation makes it difficult for joint venture and partnership possibilities to flourish. For example, there are two Cree owned petroleum distribution companies in James Bay. They both compete to service gas stations and airports. Together they could increase their volume and allow for better pricing and lowered overhead costs and so on, however this is not the case.

There seems to be an ongoing and constant battle with the provincial and federal governments. The battles end up costing the Cree several million dollars per year in consulting and legal fees. 
Obviously, it is to the advantage of lawyers and consultants that these disagreements continue. A more constructive approach would be to negotiate agreements that would benefit both sides and argue less over details. Economic opportunities are being lost when disagreements continue for extended periods. The annual legal costs incurred could also be diminished substantially and these funds could be put to better use.

Economic development has not been a priority up to now; rather, the main focus of attention has been on language, culture and tradition. Until the next generation who are currently in school become leaders, there will always be some confusion about what the Cree consider their priorities. What the Cree have is a society comprised of elders who have lived most of their lives off the land. The middle-aged group, who are the leaders are caught between modern culture and tradition, along with the bitter experiences of having had been through the residential school system. Then there is the youth who are being taught in modern schools to get a proper education go to college and get a job. It will take many years for the Cree to finally settle in to what is really going on and the direction to follow. Once the majority of the population has lived and gone through the same upbringing and share the same beliefs and priorities, a new and modern Cree society will undoubtedly emerge.

And finally the issue of taxation is still a problem. No Cree person pays taxes of any kind while on the reserve. While off the reserve however, everyone becomes a taxable individual. Also, any corporation, whether on the reserve or not, is taxable. The taxable status of a corporation is due to the fact that corporations are considered an entity on their own and thus do not posses native status. The tax issue causes certain problems for economic development. The communities will not tax their residents for municipal services rendered such as water, sewage, garbage removal, snow removal etc. Furthermore, the regional health board and the regional school board do not tax anyone or charge any fees for any of their services. This means that the Band councils and other Cree public institutions are entirely dependent on government funding. Should this funding diminish, be discontinued or should the population grow and not the funds, the communities could suffer a serious decline in services rendered and ability to operate.

The issue of paying taxes also has an effect on education. Cree students who finish high school are sometimes unwilling to attend universities in the south simply because there is a strong reluctance to having to pay taxes for anything. It would benefit all the people in the James Bay region if they would self-impose certain "Cree" taxes upon themselves. This would allow greater flexibility and opportunities to provide better services to the people. Training and educating the general public that money is not free and they should work to obtain more money would greatly improve the attitude and work ethics of the Cree labour force. It would also better prepare young people for the realities of life consistent with the rest of Canada. 


\section{Conclusion}

Considerable efforts have been made to establish a solid base for economic development for the Cree communities. The Cree have developed the James Bay region in ways that no one else could have possibly undertaken. They have advanced to a modern day society and yet have maintained a strong identity of who they are and what they represent as Canadian residents. They have modern development practices, and incorporated advanced technology but have kept their traditions and culture as strong as possible in the process.

It is important to comprehend the difficulties that the Cree have undergone in recent times and what is still in store for the future. While there are difficulties and problems associated with advancing economic development there is also a lot of good that has benefited the James Bay Cree. With the focus in the past 10-20 years on better homes, schooling and health-care the Cree have done well. Efforts will now have to shift towards developing and maintaining an acceptable social structure along with effective regional economic development that is in harmony with their culture and beliefs. The Cree have also learned, perhaps the hard way, how to negotiate and obtain funding, support and services from public and private sector sources.

One of the main elements of effective development has been the attention to effective planning and budgeting as well as training and development of the local labour market. The Cree have established community labour force development priorities and have put in place resources to monitor and evaluate the effectiveness of the local labour force and labour market initiatives. Annual training plans are prepared which detail a list of priorities for the training required as well as the necessary budgetary requirements. Most funding for these initiatives is obtained through an array of programs administered by the Cree human resources department of the Cree Regional Authority, which in turn, receives its annual training budget from Human Resource Development Canada. Annual budgets range from \$2.3-2.5 million dollars, which are set-aside exclusively for training purposes.

There are still many outstanding issues to be resolved by the Cree and the governments of Quebec and Canada. However, a peaceful resolution to these issues requires a full understanding and acceptance by all parties concerned on the meaning of equal partnership, participation and co-existence of peoples and governments. The ability of the Cree to quickly adapt to a changing social environment has been astounding considering the pace of change that have taken place. It is this adaptability and endurance that will allow the Cree to prevail and be strong business and community leaders in the James Bay region of Northern Quebec. The development process is still ongoing in James Bay and many more economic development projects are expected to evolve over the next decade or more. 


\section{Author's biography}

Mike McGee has been working as the Director of Economic Development for the Cree Nation of Wemindji for the past ten years and has lived and worked for the Cree of James Bay for over 19 years. He is also the General Manager of Tawich Development Corporation as well as Director of Operations of Creenet Inc., the only ISP in James Bay. Mike has a diploma in Economic Development from the University of Waterloo as well as memberships in various provincial economic development associations and the Canadian Aboriginal Native Development Organization (CANDO). Over the years he has been involved in Native economic development, negotiations and job creation on a full-time basis.

\section{Bibliography}

1996 Annual Report, Cree-Inuit-Naskapi, The James Bay and Northern Quebec Agreement and the Northeastern Quebec Agreement, Indian and Northern Affairs Canada, ISBN 0-662-62771-7, Catalogue No: R71-38/1996.

1998 Report from the Cree Naskapi Commission: http://ppp.atreide.net/cnc/

Basic Departmental Data, Indian and Northern Affairs, March 1998 ISBN 0-662-63-201-X Catalogue No: R12-7/1997.

Bill C-46, The House of Commons of Canada. June 8, 1984, Second Session, Thirty-second Parliament, 32-33 Elizabeth II, 1983-84.

Cree School Board, Annual Report, 1989-90.

Cree School Board, Annual Report, 1995.

Cree School Board, Annual Report, 1998.

Cree Board of Health and Social Services, Annual Report, 1986-87.

Cree Board of Health and Social Services, Annual Report, 1995-96.

Cree Board of Health and Social Services, Annual Report, 1997-98.

Cree Board of Compensation, Annual Report, 1983-84.

Cree Board of Compensation, Annual Report, 1991. 
Cree Board of Compensation, Annual Report, 1998.

Cree Nation of Mistissini website: http://nation-mistissini.qc.ca/

Cree Nation of Wemindji website: http://www.wemindji-nation.qc.ca/

Cree Status and Rights in the Context of Quebec's succession from Canada: A Matter of Equity, Logic and Fundamental Human Rights, Grand Council of the Crees, February 1992, Commission on Human Rights, $48^{\text {th }}$ Session.

Creeco Inc., Annual Report, 1990.

Creeco Inc., Annual Report, 1994.

Creeco Inc., Annual Report, 1997-98.

Creenet Inc. website: http://www.creenet.com

Grand Council of the Crees / Cree Regional Authority, Annual Report, 1986-87.

Grand Council of the Crees / Cree Regional Authority, Annual Report, 1990-91.

Grand Council of the Crees / Cree Regional Authority, Annual Report, 1997-98.

Grand Council of the Cree website: http://www.gcc.ca/

James Bay and Northern Quebec Agreement and Complimentary Agreements, Gouvernement du Quebec, Les Publications du Quebec, ISBN 2-551-14501-5.

Justice for the Cree: Communities, Crime and Order. Grand Council of the Cree / Cree Regional Authority, August 1991.

La Grande 1986 Agreement.

Milestones of the Cree School Board, 1998 Report.

Policy Supporting Local and Regional Development, Government of Quebec 1997, ISBN 2-55031618-5.

TED, Trade and Environment Database Website. 
http://www.american.edu/projects/mandala/TED/

The Aboriginal Peoples of Quebec, The Road to the Present, Government of Quebec, Secretariat aux affaires autochtones, 1991.ISBN 2-551-14856-1.

The James Bay Advisory Committee on the Environment, Annual Report 1994-1995.

\section{Interviews}

Interview with Mr. Brian Craik, Consultant for the Grand Council of the Crees. Ottawa, March 1999.

Interview with Chief Walter Hughboy, Chief of the Cree Nation of Wemindji, July 1999. 